Brit. J. industr. Med., 1955, 12, 309.

\title{
OLDER PEOPLE AND HEAVY WORK
}

\author{
BY \\ R. M. BELBIN \\ From the Nuffield Research Unit into Problems of Ageing, Psychological Laboratory, Cambridge
}

(RECEIVED FOR PUBLICATION MARCH 4, 19:5)

The proportion of older persons in the population is increasing year by year and, in anticipation of the economic consequences that this situation will bring about, growing support has developed for the proposal that more elderly people should be employed in industry. However, the prevalence of policies of age discrimination in labour intake and of compulsory retirement at fixed ages in many occupations suggests that opportunities for the employment of older people have not been developing at a rate commensurate with the need. Indeed, an inquiry carried out by Thomas (1947) for the Industrial Health Research Board reported :

"A comparison with the census of England and Wales, 1931, reveals that, contrary to what might have been expected in view of the wartime demand for labour, a lower proportion of old persons over 60 was in employment in 1945 than in 1931."

Moreover, as the proportion of older people in employment declined steeply in the two years following the war (Ministry of Labour Gazette, 1948), there are some grounds for the conclusion of the report that ... "even fewer old persons may remain in employment in the future".

It is worth noting that a similar trend has been reported in the United States. While the number of persons aged 65 and over has multiplied by over four times in the past half century the proportion of employed men aged 65 and over has fallen steadily over the same period. In $187080 \%$ of the older men were working, in $191063 \%$, in $193054 \%$, and in $194041 \%$. The percentage increased during the war but by 1950 it had declined to $45 \%$ (see Mushkin and Berman, 1947 ; Burns, 1954). A steady though less marked decline has also shown itself for employed men between 55 and 64 . A Committee on Aging and Geriatrics (1952), in presenting information on this subject, has suggested that this decline is due in large measure to the shrinking place of agriculture and self-employment generally in the national economy.

If such an interpretation is correct and applies to similar trends in Great Britain the recommendation made by the National Advisory Committee on the Employment of Older Men and Women (1953) on the need to increase the proportion of older persons employed in industry is not likely to be easily accomplished. It would appear that the demands of industrial work are less suited to the capacities of older persons than other types of work. Moreover, the problem is rendered more difficult by the fact that there is no general agreement as to the type of industrial work which is most suited to older persons. The most commonly held view is that older people should be transferred to lighter work, but the implication that industrial work is not suited to older persons because of its heaviness should not be taken for granted. Whether or not lighter work can be recommended as a policy likely to increase the number of persons working in the higher age groups depends on a careful sifting of the facts. To present data relating to this subject is the object of the paper.

\section{Previous Studies}

The first serious and comprehensive study of the older worker in industry was made by Barkin (1933) in a report prepared for the New York Joint Legislative Committee on Unemployment. In one chapter on the "Characteristics of the Older Person as a Worker" Barkin presented data on the type of work in which people of different ages tended to be found in industry. Industrial work was divided into five main groups : hand work, body work, machine work, clerical work, and supervisory and technical work. Barkin observed :

" The most striking fact presented by a study of the persons engaged at various types of work is that the percentage of persons at body work increased with advancing age, particularly after 35 years of age. While $21 \cdot 3 \%$ of the persons $30-34$ years were employed at such work, this percentage rose to 25.6 for the age group 40-44 years, to $28 \cdot 7$ for the age group 50-54 years, to $34 \cdot 3$ for the age group $60-64$ years, and to 37.5 for the age group 70 years and over."

Body work was defined as " that type of work which is performed by the application of bodily 
strength or by the use of large tools demanding bodily movements ". In a further analysis operations were divided into three grades according to the degree of physical exertion imposed-great, medium, and slight. The smallest percentage engaged on work requiring great physical exertion was the youngest age group $(5.4 \%)$, the percentage increasing with each demi-decade up to 18 in the $40-44$ age group and thereafter declining by not more than $1 \%$ per demi-decade up to the age group 70 and over where the percentage fell to $12 \cdot 4$. Even more striking were the results which Barkin obtained for those newly hired.

" The group where the older person as a class possesses the greatest hold," he observed, "is that in which the job demands great physical exertion. Approximately $26 \%$ of all the persons hired for such jobs were 40 years and over. The others follow in inverse proportion to the degree of physical exertion which is needed. Twenty-five per cent. of the men added to jobs grouped as requiring medium physical exertion were beyond 40 years of age. The proportion, however, for those requiring slight physical exertion was only $15 \%$... Among the women workers the largest percentage of older females hired in any one single class is also to be found in the jobs requiring great physical exertion (13.3). The other two classes follow in the same order as for the males, medium $(12 \cdot 6 \%)$ and then slight $(9 \cdot 7) . "$

These notable findings obtained during the years of the depression in the United States lead us to enquire how far similar tendencies exist in Britain in the post-war period when employment has been generally high. A simple answer, however, is not forthcoming as research investigators have not posed exactly the same questions as those of Barkin, but there is a certain amount of miscellaneous information which has a bearing on the type of work on which older people are employed and which relates in particular to the heaviness of the work. This information may be summarized as follows.

(1) Distribution of Older People between Different Industries.-Information relating to this subject has been presented by the Industrial Welfare Society (1950) and the National Advisory Committee on the Employment of Older Men and Women (1953). There appear to be no very marked differences as between different industries and there is no pattern that is associated with the differences in physical exertion which various industries may impose. For example, the percentage of persons employed in mining and quarrying aged between 55 and 64 is 14 and between 65 and 69 is 2.4 as against the national industrial average of 13.3 and 2.5 respectively. However, it is not known upon what jobs the older workers are actually engaged. The older workers might be employed on light work in " heavy" industry or relatively heavy work in "light" industry. The data can only be assessed if more is known about the different types of work which older people perform and their tendency to transfer from jobs which they have previously held.

(2) Distribution of Older People between Different Types of Work.-Thomas and Osborne (1950) persented data on the distribution of a sample of 1950 male workers between the ages of 55 and 74 . Dividing the types of industrial operations into the categories of professional, higher technical, managerial, clerical, manipulative, operative, and unskilled, it was found that fewer of the older men than men of the general population were operative and manipulative workers, $25 \%$ and $14 \%$ respectively against $35 \%$ and $20 \%$ in the normal population, and more of them were unskilled, $22 \%$ as against $15 \%$. Unskilled workers were defined for the purpose of the investigation as "all those whose physical strength enables them to carry out a task without training or the provision of tools other than the simplest hand tools". In a sample of 482 women in the same age range $30 \%$ of the older women were classed as operatives as against $50 \%$ in the general population and $35 \%$ of the older women were unskilled workers as against $10 \%$ in the general population.

Except for the work of Richardson, to be considered below, there is little data specifically referring to heavy work. Two studies, however, contain some mention of the subject. When male manipulative workers, operatives, and unskilled workers between the ages of 55 and 74 were questioned in the study of Thomas and Osborne (1950) as to the type of work performed in their present or last full-time job, $18 \%$ stated that they had been engaged on very heavy work and a further $38 \%$ on moderately heavy work. Comparable figures for male workers over pensionable age, i.e., over 65, were obtained in the survey carried out by the Industrial Welfare Society (1950). Replies from 349 firms showed that $17 \%$ of the elderly workers employed were engaged on heavy work, $48 \%$ on medium work, and $27 \%$ on light work. For female elderly workers of 60 years and over the figures were $1 \%, 38 \%$, and $61 \%$ respectively. But what interpretation can be placed on the data is not clear. In neither study was heavy work defined nor were the data obtained compared with those of a control group of younger men.

(3) Transfer of Older People from One Form of Work to Another.-The rates at which older people retire from the building industry and the type of change of job to which they are subject in 
later life have been studied by Le Gros Clark (1945a, 1945b, 1955). Failing health appeared to play an important part in such retirement. On the other hand moves to more amenable work in the $60 \mathrm{~s}$ and $70 \mathrm{~s}$ appeared to be fairly common irrespective of health. This usually involved, however, not so much a move to lighter work or a change in the type of work but rather a change to easier circumstances in which to carry out similar tasks. Thus the tendency is noted for older workers to engage in work which they can carry out at their own pace ; for example, it is typical for older workers to engage in maintenance work rather than in constructional work. Most of the heavy work in the building industry is probably labouring. It is worth noting here, however, that the age wastage from labouring was not greater than for other building occupations.

Apart from the data included in Le Gros Clark's studies there are only two other investigations which were specifically concerned with job change with age. These are an earlier study by the writer (1953) and a study by Richardson (1953).

In the former study evidence was given that transfers tended to occur from the early 50 s from operations which required continuous bodily movement and activity in association with a rapid tempo of work, accentuated by the payment of piece-rates or enforced by the requirements of a working team, a series of machines, or a conveyor-line. A few workers on these operations, however, were able to continue till the retiring age. On other operations older workers were rarely found to move to other work except where there were indications of failing health. Heaviness alone, i.e., with no further strain imposed by the tempo of work, did not appear to cause moves with increasing age.

In Richardson's study workers between the ages of 50 and 79 were interviewed in two foundries and a coal-mine. They were asked a number of questions relating to their work history. One question asked was whether they had ever moved from heavy to light work. Those in the 70s were more inclined to say yes than those in the 60s and those in the 60s more than those in the 50s. From the replies as to the age at which such changes had occurred Richardson calculated the probabilities or rate of transfer to lighter work for different age groups. The rate per year was extremely low for the 20 s, less than 0.01 in the $30 \mathrm{~s}$, rising to 0.05 in the $50 \mathrm{~s}$, and continuing to rise thereafter. Noting that national unemployment figures showed a sharp rise from the 40s onwards and finding an analogous tendency in his own data, Richardson reached the tentative conclusion " that the real trend of transference to lighter work is a low incidence until the 40 s and a rapid rise from then on ". Richardson's data and conclusions are re-examined later in this paper.

\section{Method and Results in Two Studies}

The data to be presented in this paper are divided into two sections. The first is concerned with the age distribution of men and women employed on heavy work and therefore corresponds with (2) opposite. It is subdivided into two parts, one dealing with a small-scale sample of operations personally studied by the author and the other a more general analysis of occupations and ages listed in the 1951 census. The second section deals with an intensive study of job change in a firm which included an unusually large proportion of heavy jobs.

\section{The Age Distribution of Men and Women Employed on Heavy Work}

Evidence from a Small Sample.-Previous data obtained by the author on the distribution of ages for certain types of industrial operation have been presented elsewhere (Belbin, 1952, see also Welford, 1951). The operations studied were divided into the following categories: Heavy and active work, machine feeding, machine operating, light assembly, and inspection. There was no apparent tendency for a larger proportion of older men or women to be employed on any one of the various categories of operation.

Heavy and active work was defined as " operations involving considerable muscular effort in the handling of heavy materials" and included "those involving a high degree of activity which made them regarded as heavy in the factories concerned ". The latter group of operations tended to be those from which older people moved away before the age of retirement and has been described in detail in a previous paper (Belbin, 1953). These operations had the effect of lowering the age distribution for the heavy and active category.

Most of the active operations were not in fact heavy in the sense that they demanded muscular exertion. But they made demands on physical movement and speed. A separation here between "heavy" and "active" seems therefore desirable. When the active operations, i.e., operations not requiring lifting or moving of heavy objects or other forms of work requiring physical exertion, are excluded from the heavy and active category there remain operations which are heavy in the sense that they require specifically lifting, moving around of heavy objects, and strenuous exertion. To this group may be added a few operations originally listed under the other categories of work 
but which also possessed the characteristics of heaviness mentioned above. The total heavy group comprised : giant tyre casemaking, the manual assembly of the cover and tread of giant tyres before the process of moulding; hide shaving involving the lifting and moving around of hides weighing $20 \mathrm{lb}$. on a shaving machine; various operations involving the handling, stencilling, and loading into lorries of paint drums and cases (most of the drums weighing $42 \mathrm{lb}$. and some of the cases handled weighing as much as $120 \mathrm{lb}$.) ; the feeding of planks weighing approximately $50 \mathrm{lb}$. into planing and sawing machines; repolishing bearings, involving the frequent lifting of trays of over $50 \mathrm{lb}$. and the application of force in pressing rings against mechanical polishers; the setting up and operating of lace machines which involved lifting heavy mechanical parts without mechanical aids ; the manual fitting of tyres on to car wheels; the handling of cylinder blocks in machine grinding; the rubbing down of cars with emery paper before cellulosing; the work of fitting in a large machine shop ; plateworking in a heavy engineering firm, a number of foundry operations taken from two firms; packing and dispatching heavy boxes (weighing up to $120 \mathrm{lb}$.) ; the work of industrial blacksmiths in a heavy engineering firm; and an operation involving stacking and storing paint tins and drums from a production line.

This group of heavy operations could be compared with other light and active operations in the samples. The active operations in the original heavy and active table from which operatives had been found to move before the retiring age were excluded from both groups. A comparison of the age distribution for the 23 heavy operations employing 1,240 men with that for the 20 light operations employing 853 men is shown in Table 1. There appears to be a stronger trend for men in the higher age groups to be found in the heavy operations than on the light operations. The difference between the two distributions is significant $(t=2.72, P<0.01)$.

The operatives in this sample included only those who were employed on production and did not include ancillary workers. However, it was apparent that many of the ancillary jobs made considerable demands on muscular effort and large proportions of older people were often employed on such work. Thus in one engineering firm those engaged on heavy labouring represented only a small percentage of the total labour force, yet two-thirds of the over70 s and $43 \%$ of the 65 to 70 s were employed on heavy labouring. In another firm which manufactured cars older men were often moved off the production lines to be placed in the stores department which was generally agreed to involve as much muscular exertion as any of the heaviest production operations in the factory.

Evidence concerning the employment of women on heavy work is difficult to obtain since women are not normally employed on such work. Nevertheless there were six women's operations in the sample studied which had been placed in the original heavy and active table but of these only three could be defined as falling within our present definition of heavy work. Two of the operations involved lifting up, labelling, and stacking heavy tins and containers. One of them necessitated periodically moving a tray of about a hundredweight on to a conveyor line. The third operation involved rigorous and continuous hand polishing of furniture alongside a production line. From the last operation (employing 26 women) there had been some tendency for the older women to move off on to other work. Yet five of the women employed were in the 40s and one was in the 50s. On the other two operations employing 15 and nine women, the mean ages of the older half of those employed were 50.8 and $57 \cdot 2$ respectively.

Evidence from the 1951 Census.-The information on the heaviness of work performed by older people given in the study above could be regarded as suggestive but no firm conclusions could be drawn because the sample could not be claimed as representative of industry as a whole. This question, however, could be pursued by detailed consideration of the larger and more representative information afforded by the $1 \%$ sample of the 1951 census. The disadvantage of such information is that the occupations listed are of necessity far more vague than in the case of a small sample where a job description can be made of each operation. A small number of occupations in the census, however, refer to work (including heavy work) which is sufficiently specific

TABLE 1

AGE DISTRIBUTION OF MEN ENGAGED IN A SAMPLE OF HEAVY AND LIGHT OPERATIONS

\begin{tabular}{|c|c|c|c|c|c|c|c|c|c|c|c|c|c|c|c|c|}
\hline & & & \multicolumn{13}{|c|}{ Age Distribution } & \multirow{2}{*}{ Total } \\
\hline & & & $\overline{16-20}$ & $21-5$ & $\overline{26-30}$ & $31-5$ & $\longdiv { 3 6 - 4 0 }$ & $41-5$ & $46-50$ & $51-5$ & $\mid \overline{56-60}$ & $61-5$ & $\mid \overline{66-70}$ & $71-5$ & $76-80$ & \\
\hline $\begin{array}{l}\text { Light operations } \\
\text { Heavy operations }\end{array}$ & $\because$ & .. & $\begin{array}{l}9 \\
2\end{array}$ & $\begin{array}{r}85 \\
104\end{array}$ & $\begin{array}{l}124 \\
149\end{array}$ & $\begin{array}{l}146 \\
169\end{array}$ & $\begin{array}{l}128 \\
163\end{array}$ & $\begin{array}{l}113 \\
184\end{array}$ & $\begin{array}{r}94 \\
177\end{array}$ & $\begin{array}{r}60 \\
112\end{array}$ & $\begin{array}{l}54 \\
74\end{array}$ & $\begin{array}{l}27 \\
72\end{array}$ & $\begin{array}{r}9 \\
22\end{array}$ & $\begin{array}{r}3 \\
12\end{array}$ & 1 & $\begin{array}{r}853 \\
1,240\end{array}$ \\
\hline
\end{tabular}


TABLE 2

HEAVY AND LABOURING JOBS COMPARED WITH SKILLED AND LESS HEAVY JOBS IN THE SAME INDUSTRIES*

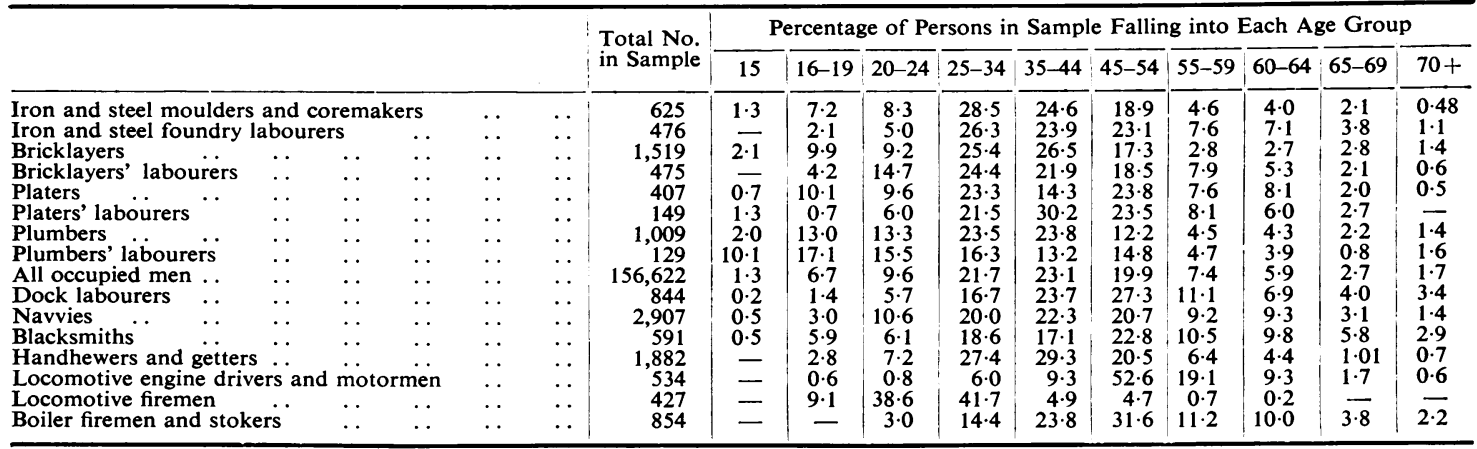

* From Census, 1951, England and Wales, Preliminary Report

to enable comparisons to be made with some confidence. This is especially the case where a skilled man or tradesman is served by a labourer who performs the heavier part of the job.

The experience of the labourer sometimes enables him to be promoted to the skilled work which he has previously served. This process, however, is usually irreversible, for the skilled worker seldom returns to labouring. This is clearly a reason for expecting the proportion of persons engaged in labouring to be lower in the older age groups than in the younger. But for each trade the extent of this will vary according to the extent to which skilled workers are recruited via apprenticeships or by promotion from those working as ancillary workers. However, the fact that there is some promotion from the ranks of the unskilled will tend to reduce the numbers which we would otherwise expect to find in the higher age groups.

The method which we shall employ in this section is to compare all recognizably heavy occupations and labouring jobs with the skilled and less heavy occupations in the same industry.

The first comparison which can be drawn is for foundry workers, between iron and steel moulders and coremakers and iron and steel foundry labourers (Table 2). The percentage of labourers in the 45-54 age group and in each successive age group is higher than the percentage of skilled workers. The same trend is apparent when a comparison is made between bricklayers and bricklayers' labourers. From the 45-54 age a higher percentage of labourers is shown than of skilled workers. In the 55-59 age group the difference is pronounced and is also marked in the 60-64 age group. However, in the 65-69 and 70+ age groups there is some indication of a reversal of these trends. In the case of platers and platers' labourers no marked difference of trends in higher age groups is at first apparent. The 45-54 age group shows virtually the same percentage. The percentage of labourers in the 55-59 age group is slightly higher than the percentage of skilled workers but after 60 there is some indication of a reversal of the trend. The same reversal of trends may be observed with regard to plumbers and plumbers' labourers. The percentage of plumbers' labourers is slightly higher for the 45-54 and 55-60 age groups but thereafter the trend is reversed although the differences are not significant. Plumbing is a good example of an occupation in which persons become tradesmen via labouring; many of the younger plumbers' labourers are in fact apprentices learning the trade. Thus there is a high proportion of plumbers' labourers among the under-20s. Yet in spite of the drift of plumbers' labourers into plumbing the percentage of plumbers' labourers in the higher age groups is not markedly diminished.

A number of other heavy occupations are recognizable from the census. These are dock labourers, navvies, blacksmiths, and handhewers and getters shown in Table 2. All four occupations show higher percentages in the 45-54 age group than for all occupied men. The dock labourers, navvies, and blacksmiths show high percentages of persons in each of the higher age groups, excepting only the $70+$ age group in the case of the navvies. The handhewers and getters, whose occupation at the coal face must be reckoned as one of the most arduous industrial operations, show slightly lower percentages than for all occupied men from the age of 55 .

The youngest age distribution of any heavy operation undoubtedly belongs to locomotive firemen. One notes the marked difference between 
the age distribution for locomotive firemen and for that of the skilled workers whom they assist, i.e., locomotive engine drivers. The reason for this is simply that locomotive firemen are usually promoted from this grade of work and normally to engine driving by the age of 40 . This is the extreme case of an unskilled occupation serving as an apprenticeship for the skilled job. It is interesting to note, however, that an occupation comparable in many respects with that of locomotive firemen but one from which there is no recognized channel of promotion, i.e., that of boiler firemen and stokers, shows a relatively older age distribution, although after the age of 65 there is a sharp decline.

In summary of this section then it would appear, when comparison is made between skilled and unskilled jobs within the same occupation group, that in spite of the tendency for promotion to reduce the numbers of persons in the higher age groups, fairly large numbers of older persons still tend to be employed on ancillary and service operations. Heavy labouring, together with a number of other recognizably heavy occupations, contains relatively high proportions of persons in the higher age groups especially between the ages of 45 and 60 . There is, however, some indication of a reversal of this trend after the customary age of retirement, 65, when persons engaged on the more skilled trades appear to hold a firmer grip on their jobs than do persons engaged on heavy unskilled work.

Before finally passing from this section it seems worth referring to an indication of comparable trends in the United States. The Committee on Aging and Geriatrics (1952) gives information on the major occupation groups of employed persons by age for the month of January, 1952. While heavy work is not mentioned as such, the results are revealing if we bear in mind that most heavy work in industry is usually covered by labouring and service operations. Below the age of 45 operative and kindred persons form $21 \%$ of employed persons while service workers (excepting those in private households) form $8 \%$. But while the percentage of operatives employed in the age groups 45-54, 55-64, and 65 and over shows a decline with figures of $19 \%, 17 \%$, and $10 \%$, the service workers show an increase with age with figures of $8 \%, 10 \%$, and $13 \%$ respectively.

The Allocation of Heavy Work in One Factory

Heavy operations in industry are often those which have been long established. Newer operations tend to be more highly mechanized and therefore usually involve little physical exertion. It may be largely for this reason that older operatives are employed on the heavy (i.e., long established) operations while younger labour is placed on operations which are newer and lighter. This is likely to occur where the mobility of labour within a firm is low.

An opportunity to consider the relationship between age and heavy work where internal labour mobility in a factory is high was afforded by a firm which manufactured batteries. In order to minimize any possible risk of lead poisoning operatives were periodically switched from one department to another and from job to job. There were four departments whose operatives were interchangeable and in each of the departments there was a considerable amount of heavy work.

A Hollerith card was provided in the firm for every job carried out during each day or part of a day. The information on the card included the date, the clock number of the operative, the job, clocked hours, and earned hours. It was thus possible to obtain a detailed record of the jobs held by each worker throughout the year. Over 100,000 job cards were analysed for 327 men employed on 34 operations.

Before the final results were worked out the author asked the time study department (which was responsible for fixing the fatigue allowances for the operations) to place the operations into five grades according to the degree of physical exertion required. Grade I indicated very heavy work, Grade II heavy work, Grade III moderately heavy work, Grade IV moderately light work, and Grade V light work.

The records could be handled in a number of ways. The most straightforward analysis could be carried out by counting the number of job cards falling into each grade for each of the age groups. The percentage of work done by older workers on this criterion is shown for each grade in Table 3.

TABLE 3

PERCENTAGE OF WORK DONE BY OLDER WORKERS ACCORDING TO DEGREE OF PHYSICAL EXERTION REQUIRED

\begin{tabular}{|c|c|c|c|c|c|}
\hline & I & II & III & IV & $\mathrm{V}$ \\
\hline No. of operations in each grade & 4 & 4 & 11 & 12 & 3 \\
\hline \begin{tabular}{cccc} 
No. of persons & \multicolumn{3}{c}{ who } \\
each grade &. &. &. \\
\end{tabular} & 35 & 63 & 283 & 312 & 90 \\
\hline 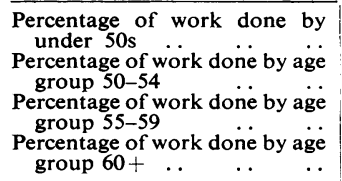 & $\begin{array}{l}35 \cdot 8 \\
23 \cdot 5 \\
23 \cdot 4 \\
17 \cdot 3\end{array}$ & $\begin{array}{r}81 \cdot 7 \\
14 \cdot 2 \\
3 \cdot 9 \\
0 \cdot 2\end{array}$ & $\begin{array}{r}71 \cdot 1 \\
17 \cdot 7 \\
9 \cdot 1 \\
2 \cdot 1\end{array}$ & $\begin{array}{r}73 \cdot 5 \\
13 \cdot 8 \\
7 \cdot 5 \\
5 \cdot 2\end{array}$ & $\begin{array}{c}89 \cdot 5 \\
10 \cdot 5 \\
0 \\
0\end{array}$ \\
\hline
\end{tabular}

It will be seen that the heaviest operations showed the highest proportion of work done by older 
persons. The lightest operations showed the smallest proportion of work done by older workers.

In the above classification the number of job cards was clearly a far less exact indication of the amount of work done than the amount of time spent on each job. One of the reasons for this was that some operations tended to carry with them a larger number of job cards than others. While the time spent on each job was recorded on the job cards the information had not been separately extracted during the automatic computation for reasons of financial economy. The sheets contained information on jobs in chronological order and to have obtained information on the total time spent on the various jobs would have meant that all the cards would have had to be analysed twice. It was possible, however, to find out the actual time spent on the various jobs for a small group. Accordingly all those in the age range 55-65 were compared with a sample of equal size in the 25-35 age range in respect of the number of hours spent on the different grades of work (Table 4).

TABLE 4

HOURS SPENT ON WORK GRADED ACCORDING TO PHYSICAL EXERTION (TO NEAREST HOUR)

\begin{tabular}{|c|c|c|c|c|c|c|}
\hline $\begin{array}{l}\text { No. in } \\
\text { Sample }\end{array}$ & $\begin{array}{c}\text { Age } \\
\text { Group }\end{array}$ & I & II & III & IV & $\mathrm{V}$ \\
\hline $\begin{array}{l}22 \\
22\end{array}$ & $\begin{array}{l}55-65 \\
25-35\end{array}$ & $\begin{array}{r}2,311 \\
73\end{array}$ & $\begin{array}{l}2,312 \\
5,572\end{array}$ & $\begin{array}{l}16,707 \\
17,917\end{array}$ & $\begin{array}{l}14,436 \\
13,203\end{array}$ & $\begin{array}{r}0 \\
503\end{array}$ \\
\hline
\end{tabular}

It will be seen that the greatest differences between the two groups occur in the extreme grades, the overwhelming proportion of the very heavy work being done by the older people and all the very light work being done by the younger people.

It may be seen from Tables 3 and 4 that while notable differences showed themselves between the age groups in the two extreme grades most of the work carried out fell into grades III and IV. The operations in these two grades included both production and non-production jobs. The existence of a large number of non-production jobs reflected the fact that production workers were often taken off their own jobs and placed on to unskilled work. This was because fluctuations in demand, linked especially with seasonal factors, affected the manufacture of the product concerned to a considerable extent. When the data presented in Grades III and IV of Table 4 were analysed in terms of production and non-production jobs (Table 5) it became clear

TABLE 5

JOBS IN GRADES III AND IV (FROM TABLE 4) SUBDIVIDED ACCORDING TO PRODUCTION AND NON-PRODUCTION JOBS

\begin{tabular}{|c|c|c|c|c|c|c|}
\hline \multirow{2}{*}{$\begin{array}{c}\text { Age } \\
\text { Group }\end{array}$} & \multicolumn{3}{|c|}{$\underset{\text { (Hours Worked) }}{\text { III }}$} & \multicolumn{3}{|c|}{$\stackrel{\text { IV }}{\text { (Hours Worked) }}$} \\
\hline & Total & $\begin{array}{c}\text { Produc- } \\
\text { tion }\end{array}$ & $\begin{array}{l}\text { Non- } \\
\text { produc- } \\
\text { tion }\end{array}$ & Total & $\begin{array}{c}\text { Produc- } \\
\text { tion }\end{array}$ & $\begin{array}{l}\text { Non- } \\
\text { produc- } \\
\text { tion }\end{array}$ \\
\hline $\begin{array}{l}55-65 \\
25-35\end{array}$ & $\begin{array}{l}16,707 \\
17,857\end{array}$ & $\begin{array}{r}9,104 \\
17,018\end{array}$ & $\begin{array}{r}7,603 \\
839\end{array}$ & $\begin{array}{l}14,436 \\
13,203\end{array}$ & $\begin{array}{l}11,613 \\
13,013\end{array}$ & $\begin{array}{r}2,823 \\
190\end{array}$ \\
\hline
\end{tabular}

that the older people were given a considerably larger share of the non-production jobs than the younger ones. In other words it would seem that younger workers had "first preference". This might explain why some of the heaviest work was carried out by older people since it was work that younger people would be less willing to undertake. This is not to say that older workers were on heavier and unskilled work because they had never had an opportunity to engage on other types of work, for all people in the three departments concerned were supposed to move periodically between jobs. In order to ascertain how far this was true a check was made on the total number of jobs held by all people during a year. The results of the analysis are shown in Table 6 . It will be seen that not all operators changed their jobs during the period of observation, but the chief point of interest is that the older people changed their jobs at least as frequently as younger people. Indeed there is a significant tendency for internal job transfer to increase with age. This is of considerable interest in view of the fact that the tendency for external labour turnover to decrease with age is marked and has been well authenticated (Kitson, 1925 ; Miles

TABLE 6

THE RELATIONSHIP BETWEEN AGE AND INTERNAL JOB TRANSFER : NO. OF JOBS HELD BY 327 MEN IN THREE DEPARTMENTS OF FACTORY DURING A YEAR

\begin{tabular}{|c|c|c|c|c|c|c|c|c|c|c|c|c|c|c|c|}
\hline $\begin{array}{c}\text { Age } \\
\text { Group }\end{array}$ & $\begin{array}{l}\text { Mean No. of } \\
\text { Jobs Held per } \\
\text { Age Group }\end{array}$ & 1 & 2 & 3 & 4 & 5 & 6 & 7 & 8 & ! & 10 & 11 & 12 & 13 & 14 \\
\hline $\begin{array}{l}60 \mathrm{~s} \\
50 \mathrm{~s} \\
40 \mathrm{~s} \\
30 \mathrm{~s} \\
20 \mathrm{~s}\end{array}$ & $\begin{array}{l}7.00 \\
6.24 \\
4.97 \\
3.53 \\
3.46\end{array}$ & $\begin{array}{r}-3 \\
10 \\
46 \\
18\end{array}$ & $\begin{array}{r}1 \\
5 \\
6 \\
14 \\
12\end{array}$ & $\begin{array}{r}7 \\
8 \\
15 \\
6\end{array}$ & $\begin{array}{r}\overline{2} \\
9 \\
9 \\
16\end{array}$ & $\begin{array}{r}7 \\
9 \\
16 \\
6\end{array}$ & $\begin{array}{r}7 \\
11 \\
7 \\
2\end{array}$ & $\begin{array}{r}4 \\
4 \\
6 \\
10 \\
6\end{array}$ & $\begin{array}{l}0 \\
5 \\
4 \\
2\end{array}$ & $\begin{array}{r}-4 \\
3 \\
4 \\
2 \\
2\end{array}$ & $\begin{array}{r}-4 \\
2 \\
2 \\
-\end{array}$ & $\begin{array}{r}-2 \\
1 \\
1 \\
-\end{array}$ & $\begin{array}{r}1 \\
0 \\
1 \\
- \\
-\end{array}$ & $\begin{array}{l}-3 \\
1 \\
-\end{array}$ & $\frac{\overline{2}}{1}$ \\
\hline
\end{tabular}

There is a significant correlation between age and job transfer $(\mathrm{r}=0.288, \mathrm{P}<0.001)$ 
1935 ; Schonfield, 1950 ; Long, 1951 ; Wallace, 1951 ; Jefferys, 1954). That the reverse trend exists within a firm may be due to the greater experience of the older workers and therefore the greater readiness of the management to place them on to a wider range of jobs according to the dictates of circumstance. However, this is a matter that must be pursued elsewhere. The relevance of the data for our present problem is that they illustrate that older people were not employed on heavier jobs because they suffered greater restriction of opportunity from working on other types of job : rather it can be concluded that while they worked for some time on the less heavy operations and the production jobs of Grades III and IV they would hold such jobs for relatively short periods and incline more towards the heavy and the non-production operations.

\section{Discussion}

The evidence presented in the review and study above makes it plain that it is not uncommon for the heavy jobs in industry to be carried out by older workers. In a previous paper the author (1953) has presented information concerning the type of operations from which older people tend to move before the age of retirement. Operations which gave evidence of such moves were relatively few and the number of older persons affected, other than those suffering ill-health, appeared to be small. Such information would appear to be in line with the evidence presented in this paper which has shown some tendency for older persons to te engaged on those jobs in industry which make demands on physical exertion. However, the evidence cannot be regarded as unequivocal. Richardson (1953), in an important study in this field, gave evidence to indicate that moves of older persons from heavy to lighter work were common. His general conclusion that "the real trend of transference to lighter work is a low incidence until the 40s and a rapid rise from then on "does not appear to match the evidence presented in this study. The reasons for this apparent discrepancy must be considered.

Two explanations may be suggested.

(1) The different criteria adopted by the writer and Richardson may be responsible for the general difference in the results and conclusions. For example, moves where ill-health was a factor in the change were excluded from the writer's sample but included in Richardson's sample. As it is well known that health tends to decline with age this might account for the different trends noted.

Different criteria may also have proved of importance with regard to the "heaviness" of the operations considered in the two studies. Heaviness has not been adequately defined in industrial studies of ageing, for example, in terms of the oxygen requirements associated with various forms of work. Comparison therefore of the results obtained by Richardson with those obtained by other workers may prove difficult since no criteria for comparison exist. It is thus possible that the operations considered by Richardson in the coalmine and foundries were more arduous than the " heavy" operations studied in other investigations and the tendency for older workers to move away from these operations might therefore be the greater.

(2) An alternative interpretation may be proposed for the results that Richardson presents. It may be noted that conclusions reached depend on the replies to certain questions. The persons interviewed, aged between 50 and 79, were asked about their work history, whether they had ever moved from heavy to light work, and if so at what age the move occurred. The rates of transfer per year were based on what the older people remembered about their jobs when younger. Thus the rates of transfer for the 20s were calculated from the replies of those in the 50s and over. There are grounds here for believing that forgetting about a change that had occurred 30 years earlier might account for the very low figures extrapolated for the younger age groups. This hypothesis may be followed up by examination of the data in Fig. 1 of Richardson's paper. The rate of transfer per year appears to be approximately twice as great when calculated on the basis of the replies of persons interviewed for whom that age group was the preceding age period as when the rate of transfer is calculated from the replies of those who are older than the age group in question by more than one age period. For example, for the 50-54 age group the rate of transfer per year as reckoned from the replies of those aged 55-59 is 0.0512 but as reckoned from the replies of those aged 60-64 the figure is 0.0202 . If we may suppose that a person interviewed is more likely to recall correctly a change to lighter work that was made in the last age period over one that was made more remotely in the past, re-examination of the data on this basis becomes desirable. Thus when rates of transfer are considered for the age period preceding age of interview the following Table* may be drawn up :

\begin{tabular}{c|c}
\hline Age Group & $\begin{array}{c}\text { Rate of Transfer } \\
\text { per Year }\end{array}$ \\
\hline $40-49$ & 0.0296 \\
$50-54$ & 0.0512 \\
$55-59$ & 0.0676 \\
$60-64$ & 0.0790 \\
$65-69$ & 0.0666 \\
\hline
\end{tabular}

* Extracted from Richardson's paper, Appendix, Tables A and B. 
The only notable feature of the Table appears to be the sharp rise in the rate of transfer between the 40s and the early 50s. In all probability, however, this is to some extent an artefact as the figure given for the 40s is for a 10-year period and based on the replies of those who are removed from the possible age of transfer by a span of from one to 14 years whereas for the other age groups, which cover five-year periods, the span is from one to nine years. On our present hypothesis this should have the effect of reducing the incidence of those who recalled changing to light work in their 40s. Thus we are left with a rise of from 0.0512 in the early 50 s to 0.0666 in the late 60 s.

Our conclusion concerning Richardson's data is that there seems no real evidence to indicate a move away from heavy work at least before the 50s. But there is some evidence in the two foundries and coal-mine studied of a tendency to move on to lighter work in the 50s and 60s. In the two foundries the tendency for older workers to be engaged on the lighter work is slight but not significant, but in the coal-mine the association is significant at the $5 \%$ level. It is important, however, to bear in mind what the term light or lighter work covered. Richardson states :

" Indeed the most important component of "light" or 'lighter' work, as these terms were used by the men interviewed, was his opportunity to control the pace of work and the distribution of rest pauses ... it is important to emphasize that men often moved to lighter work yet still remained in the moderate category or even (in a few cases) in the heavy category. Provided the effort was broken up by rest pauses, the intensity of effort seemed of secondary importance. .."

The replies of those interviewed as to the features of work which caused difficulty also indicate that heaviness was not of sole or prime importance. Richardson states that the outstanding reply given was about the effects of speed. Even in the case of very heavy work it was not the heaviness of work as such that was to the fore. Thus the older miners complained of shortness of breath in getting to the coal face and keeping up with the younger men but once at the coal face worked without visible distress and the remark repeatedly made was: "At my job I'm all right".

This internal evidence is in line with evidence previously produced by the writer (1953). In a study of operations from which older people tended to move before the age of retirement the work was generally referred to as heavy in the factories concerned. But most of the operations did not in fact involve heaviness in the normally accepted use of the term, i.e., in the sense of work requiring concentrated effort as in lifting, pushing, pulling, and so on, but rather the work involved more typically active movement the pace of which was determined externally, i.e., by the demands of a team, machine, or conveyor. Thus " heavy" was used in a functional rather than a descriptive sense. Similarly in the case of the "light" work to which older people moved the demands of the job often did not appear to be light at all for they frequently required lifting and other forms of concentrated effort.

While there is some tendency for older workers to move from certain types of heavy work, it is nonethe-less apparent that there is a tendency for older workers to be found on many operations requiring physical effort. Richardson points out, however, that the absolute numbers of persons involved on heavy work at the upper end of the age scale is often small. This applied also to the data for the battery factory considered in Table 6 . Richardson concludes that the small numbers in the higher age groups reflect changes by older people to lighter work.

It is clear that such a tendency exists but its interpretation seems open to doubt. While it could indicate a general tendency for older people to move towards lighter operations on account of declining capacity to work, it might also indicate no more than that the amount of heavy work in industry is declining. While both processes may operate to some extent, the former process has perhaps been over-emphasized at the expense of the latter as may be indicated by the evidence from the studies of age distribution on heavy and light work. These show not only that the numbers of older persons employed on heavy work are small but that the numbers of younger persons so employed are small also. Moreover such studies do not bear out the theory that older people gravitate towards lighter production operations since they seldom appear to be present in large numbers on such work.

The case of the battery factory considered earlier also does not support the notion that older people on heavy jobs gravitate towards the lighter operations. There was ample light work in the departments studied to which older workers might have moved. The rate of internal job transfer in these departments was high (being carried out in the interests of health) and older workers actually moved from job to job more frequently than younger persons. Yet the pattern of the very heavy work tending to be carried out by older people and the very light work by younger people still held good. The most likely interpretation is that the older people tended to work more on the heavy than light operations because younger 
workers were preferred for the latter. The ability to cope with machine work and the ability to act with the necessary speed of reaction-abilities closely associated with light work-were said to be more in evidence amongst the younger people.

Where older people have difficulty in maintaining their performance it would seem then that in general they do not move on to the lighter operations for which there is in fact more competition, but rather they move away from production work. They move, therefore, into ancillary jobs and become gatekeepers, night watchmen, and so on, or they move on to labouring jobs which tend to be heavy but where they can work at their own speed.

It seems likely then that there is some tendency in industry for older people to incline towards heavy work. In a previous paper the writer (1953) has shown that older workers transferred from active production line operations tended to be placed on reavy labouring jobs or work in the stores involving manual handling of heavy parts. More specific evidence on this subject has come from Barkin (1933). In an analysis of the jobs on to which rewly hired workers were placed Barkin found that it was on the operations requiring greatest physical exertion that the newly hired older workers had the greatest hold.

That older people should be engaged on or deliberately placed on to heavy work does not of course infer any suitability either in terms of capacity or preference. Indeed, in the study of Thomas and Osborne (1950) $69 \%$ of the older people interviewed, i.e., those between the age of 55 and 74, employed on very heavy labouring, found their work a strain-almost twice as high a percentage as on the types of work involving less physical labour.

Nor does the fact that older workers are placed on work making demands on effort rather than speed necessarily mean that the decline in physical strength with age is less than the decline in speed of movement. Indeed some of the evidence indicates otherwise. For example, the decline in pull or strength of grip seems relatively greater with age than the decline in speed of blow, in reaction time, or in speed of movement (see Ruger and Stoessiger, 1927 ; Fisher and Birren, 1947). But this difference in terms of maximum performance does not necessarily translate itself into a difference in achievement in the industrial situation. In semi-skilled operations where demands are made largely on speed of performance (once the initial skill has been acquired) decline in speed may bring about a decline in output of a corresponding order. On unskilled operations, on the other hand, where the main demand is on effort, loss of strength will not necessarily show itself as any obvious disadvantage, for maximum strength is seldom, if ever, demanded. Rather it may only mean that older people experience greater strain in coping with a given work schedule than younger people. But this they are prepared to do for it is only by dint of such effort that older workers are able to maintain their security of employment.

Finally a few words may be said about the practical implications of the theme presented. It will be seen that the proposal to make work lighter in order to help older workers might not have this effect at all. A lighter operation is likely to be one on which the emphasis will change demands from effort to speed, and the capacity of older workers to carry out the task efficiently relative to the capacity of younger workers may well be lower.

The effects which the growing introduction of lighter work will have on the employment of older workers will depend on circumstances-on the attitude of management (i.e., whether management is willing to cushion older workers), on such governmental measures as may encourage firms to employ older persons, and finally on the supply and demand of labour. If sufficient younger labour is available the increase in the amount of light work might tend to increase the employment difficulties of older people. But if labour is scarce older people may stand to gain in that they may be able to continue longer in work through the reduction in the amount of effort that the work involves without their hold on the work being reduced by younger competitors.

Where the effort is taken out of skilled work the older worker is likely to derive the greatest advantage, for if the older worker's hold on the job depends on his skill rather than his capacity for effort or speed, the elimination of the " heaviness" from an operation will not impair his competitiveness vis-à-vis younger workers but rather it will improve it by eliminating that aspect of the work in which he is inferior.

It would appear then that the possession of skill offers the worker a surer opportunity of employment in later life than does the prospect of lighter work. At present it is clear that high percentages of workers reaching middle and late maturity possess no recognized skill and have little chance of entering into skilled work owing to the barriers against training and apprenticeship which exist in respect of age. There are grounds therefore for believing that the most progressive and far-reaching approach to this problem would rest with new plans and policies for training and retraining workers before they 
become old. It is a matter for research and for industrial experimentation to show if and how this project can be undertaken successfully.

\section{Summary}

An investigation into the age distribution of persons employed on heavy work in industry is described. In a sample of operations studied, the tendency was found for a larger proportion of persons in the late $40 \mathrm{~s}$, the $50 \mathrm{~s}$, and the $60 \mathrm{~s}$ to be engaged on heavy work than on light operations. Similar findings appeared from an analysis of occupations and jobs listed in the 1951 census. Those occupations which could be recognized as heavy and strenuous tended to have a higher proportion of persons engaged on them between the ages of 45 and 60 than did lighter skilled operations in the same industries.

An opportunity of studying job changes of different age groups as between light and heavy work was provided by a large factory in which frequent job changes were carried out in order to minimize any possible risk of lead poisoning. Although most workers carried out a number of varied jobs during the year which involved experience of both light and heavy work, the heaviest work tended to be carried out by the older workers and the lightest by the younger workers. In the intermediate grades there vas a tendency for older workers to be engaged predominantly on the nonproduction jobs.

The findings suggest some difficulty in the application of the commonly accepted formula that older people should be given light work. On light production work it appears that older people face serious competition vis-à-vis younger workers, while on non-production work, consisting typically of labouring and other heavy manual jobs, it is easy for them to find employment. Improvement in the level of skill of older workers would appear to offer more promising hope of employment in later life than would the increased provision of light work, and the need for the development of facilities for training and retraining older workers is emphasized.
The work described in this article was sponsored by the Human Factors Panel of the Committee on Industrial Productivity. The author would like to express his thanks to those who helped to make this paper possible and who gave guidance and criticism, especially to the Director of the Nuffield Research Unit, Mr. A. T. Welford, to Dr. D. Malcolm, Dr. J. Szafran, and Miss J. G. Wallace.

\section{REFERENCES}

Barkin, S. (1933). The Older Worker in Industry. A Report to the New York Joint Legislative Committee on Unemployment. Legislative State Document No. 60. Lyon, Albany.

Belbin, R. M. (1952). A Study of the Employment of Older People in Industry. Cambridge University Library. Unpublished Ph.D. Thesis.

(1953). Occup. Psychol., $27,177$.

Burns, R. K. (1954). Amer. J. Sociol., 59, 384

Census 1951, England and Wales, Preliminary Report, 1951. H.M.S.O. London.

Clark, F. Le Gros (1954a). The Later Working Life in the Building Industry. A Study of 320 Ageing Maintenance Workers. Nuffield Foundation, London.

(1954b). The Working Fitness of Older Men. A Studv of Men over Sixty in the Building Industry. Nuffield Foundation, London.

- (1955). Ageing Men in the Labour Force. The Problems of Organizing Older Workers in the Building Industry. Nuffield Foundation, London.

Committee on Aging and Geriatrics (1952). Fact Book on Aging. U.S. Federal Security Agency.

Fisher, M. B., and Birren, J. E. (1947). J. appl. Psychol., 31, 490

Industrial Welfare Society (1950). The Employment of Elderly Workers. Report of a Survey on the Practice and Experience of 400 Member Firms. London.

Jefferys, M. (1954). Mobility in the Labour Market, Employment Changes in Battersea and Dagenham, pp. 60-65. Routledge and Kegan Paul, London.

Kitson, H. D. (1925). The Psychology of Vocational Adjustment, pp. 42-46. Lippincott, Philadelphia.

Long, J. R. (1951). Labour Turnover under Full Employment. Studies in Economics and Society. Univ. of Birmingham, Monograph A2, pp. 64-70.

Miles, W. R. (1935). In C. Murchison (Ed.), A Handbook of Social Psychology, pp. 596 f. Clark University Press, Worcester, Mass.

Ministry of Labour Gazette (1948). Industrial Analysis of Employment of Elderly Persons, 56, 226.

Mushkin, S. J., and Berman, A. (1947). Soc. Secur. Bull., 10, No. 8,

Nationai Advisory Committee on the Employment of Older Men and Women (1953). First Report. Ministry of Labour and National Service. H.M.S.O. Cmd. 8963.

Richardson, I. M. (1953). British Journal of Industrial Medicine, $10,269$.

Ruger, H. A., and Stoessiger, B. (1927). Ann. Eugen., Camb., $2,76$. Schonfield, A. E. D. (1950). The Training of Older People in Industry. Nuffield Research Unit Report No. 13.

Thomas, G. (1947). The Employment of Older Persons. An Inquiry carried out in mid-1945 for the Industrial. Health Research Board of the Medical Research Council. Social Survey.

-, and Osborne, B. (1950). Older People and their Employment. An Inquiry made by the Social Survey for the Ministry of Labour and National Service. Central Office of Information, London.

Wallace, J. G. (1951). A Study of Labour Turnover in a Factory in Relation to Age. Private communication.

Welford, A. T. (1951). Skill and Age. Oxford University Press, London. 